\title{
Role of fine needle aspiration cytology in the diagnosis of thyroid lesions
}

\author{
Bhatta $\mathrm{S}^{1}$, Makaju $\mathrm{R}^{2}$, Mohammad $\mathrm{A}^{2}$ \\ ${ }^{1}$ Department of Pathology, KIST Medical College, Lalitpur, Nepal \\ ${ }^{2}$ Department of Pathology, Kathmandu University School of Medical Sciences, Dhulikhel, Nepal
}

\author{
Keywords: \\ Fine needle aspiration; \\ Thyroid; \\ Neoplasm; \\ Histopathology
}

\begin{abstract}
Background: Fine needle aspiration cytology is regarded as a gold standard investigation in diagnosis of thyroid swellings. This study was carried out to evaluate the role of fine needle aspiration cytology as a diagnostic tool in investigation of thyroid swelling and to correlate the cytological findings with histopathology.
\end{abstract}

Materials and Methods: A total of 90 patients with thyroid lesions submitted for fine needle aspiration cytology at Dhulikhel hospital Kathmandu Univeristy hospital over a four year period (May 2004 to May 2008) were studied.

Results: Majority of cases were non neoplastic (77 cases, $85.55 \%$ ), whereas 13 cases (14.45\%) were neoplastic. Tissue examination was available for subsequent histocytological correlation in 20 cases $(22.22 \%)$. The accuracy of cytodiagnosis was $90 \%$ with a sensitivity of $85.7 \%$, specificity of $92.3 \%$, false negative rate of $14.28 \%$ and false positive rate of $7.69 \%$.

Conclusion: Fine needle aspiration cytology of thyroid lesions provides a reliable diagnosis and is an excellent first line method for investigating the nature of lesion.

\section{INTRODUCTION}

Fine needle aspiration cytology (FNAC) is a wellestablished technique for pre-operative investigation of thyroid nodule. ${ }^{1}$ The technique is painless and provides a more accurate diagnosis of the solitary thyroid nodule. FNAC can provide an unequivocal benign diagnosis in $60 \%$ of patients with benign nodules, its potential to reduce the number of unnecessary surgery is significant. ${ }^{2}$ Investigators have shown that FNAC is the single most sensitive, specific and cost-effective method in the investigation of solitary cold thyroid nodule. ${ }^{3}$ The aim of this study was to determine

\section{Correspondence:}

Dr. Sushama Bhatta, $M D$

Department of Pathology, KIST Medical College and Teaching Hospital

Lalitpur, Nepal

E-mail:sushmabhatta@gmail.com the role of FNAC in detection of thyroid swelling and to correlate the finding with tissue biopsy.

\section{MATERIALS AND METHODS}

This was a retrospective study carried out at Dhulikhel hospital Kathmandu University Hospital, Department of Pathology over a period of 4 years (May 2004 to May 2008). Ninety patients of all age group and both sexes who underwent FNAC for thyroid swelling were evaluated. Out of 90 patients, histopathological diagnosis was available in 20 patients.

The data was collected from computer database. The original fine needle aspiration slides stained with Wright and Papanicolaou (PAP) stains and histopathology slides 


\begin{tabular}{lc} 
Table 1. FNAC findings of 90 patients \\
\hline FNAC diagnosis & Number of patients (\%) \\
\hline Non neoplastic & $58(64.45 \%)$ \\
\hline Goiter & $13(14.45 \%)$ \\
\hline Benign cyst & $3(3.33 \%)$ \\
\hline DeQuervains (Subacute) thyroiditis & $2(2.22 \%)$ \\
\hline Lymphocytic thyroiditis & $1(1.11 \%)$ \\
\hline Hashimoto thyroiditis & \\
\hline Neoplastic & $9(10 \%)$ \\
\hline Papillary carcinoma & $3(3.33 \%)$ \\
\hline Follicular neoplasm & $1(1.11 \%)$ \\
\hline Anaplastic carcinoma & $\mathbf{9 0}(\mathbf{1 0 0} \%)$ \\
\hline Total
\end{tabular}

Table 2: Results of 20 patients of FNAC with histopathological correlation

\begin{tabular}{lccc}
\hline \multirow{2}{*}{ FNAC results } & \multicolumn{2}{c}{ Histolopathologic findings } & \multirow{2}{*}{ Total } \\
& Neoplastic & Non-neoplastic & \\
\hline Neoplastic & 6 & 1 & 7 \\
Non-neoplastic & 1 & 12 & 13 \\
\hline Total & $\mathbf{7}$ & $\mathbf{1 3}$ & $\mathbf{2 0}$ \\
\hline
\end{tabular}

Table 3: Statistical analysis for detection of malignant lesions

\begin{tabular}{lc}
\hline Sensitivity & $85.7 \%$ \\
Specificity & $92.3 \%$ \\
FPR & $7.69 \%$ \\
\hline FNR & $14.28 \%$ \\
\hline Accuracy & $90 \%$ \\
\hline
\end{tabular}

stained with Hematoxylin and eosin (HE) were reviewed. Unsatisfactory slides were excluded from the study.

FNAC and histology results were classified as nonneoplastic and neoplastic. Pre-operative FNAC results were compared with final histological diagnosis in 20 patients. The sensitivity, specificity, accuracy, false positive rate (FPR) and false negative rate (FNR) of FNAC for detection of malignant lesions was calculated. Data analysis were carried out using the Statistical Package for Social Science (SPSS, version 17) for Windows.

\section{RESULTS}

FNAC was performed on thyroid swelling of 90 patients, which included $72(80 \%)$ females and $18(20 \%)$ males with M:F ratio of 1:4. The FNAC results revealed 77 cases $(85.55 \%)$ as non neoplastic and 13 cases $(14.45 \%)$ as neoplastic (Table 1).

The commonest lesion in thyroid gland was goiter. Among the malignant neoplasms, the commonest lesion was

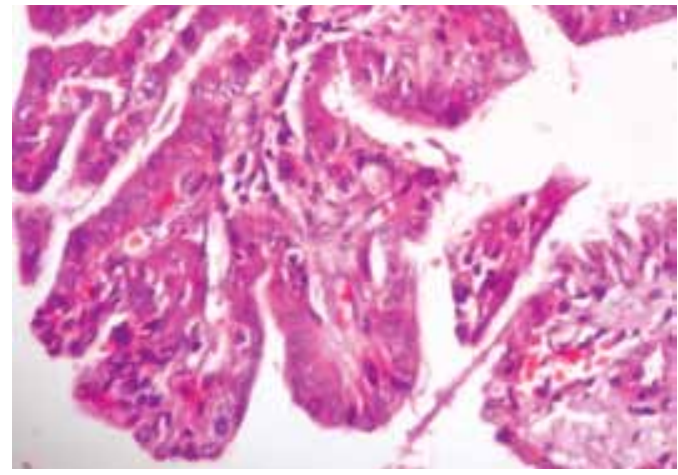

Figure 1: Papillary carcinoma showing tumor cells arranged in papilla (HE stain, X400).

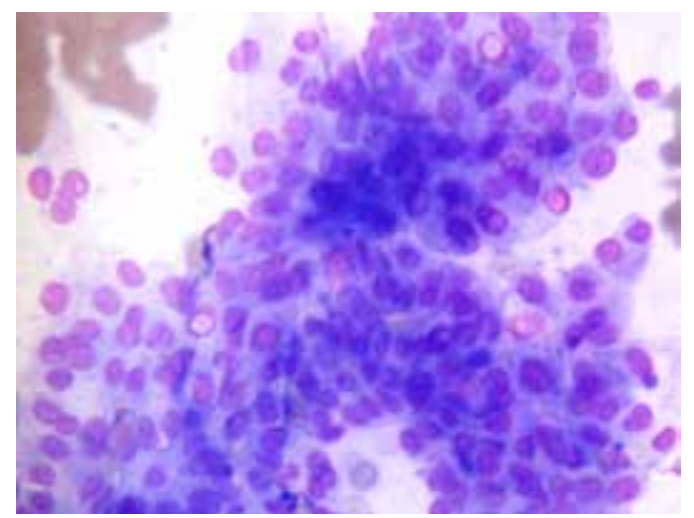

Figure2: FNAC smear from a case of papillary carcinoma showing papilla and intranuclear cytoplasmic inclusion (Wright stain, X400).

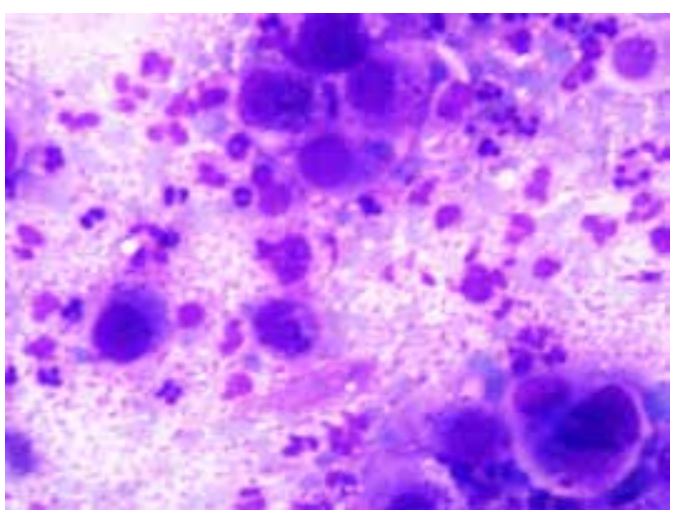

Figure 3: Anaplastic carcinoma showing hyperchromatic pleomorphic tumor cells. Background shows neutrophils (Wright stain, X400).

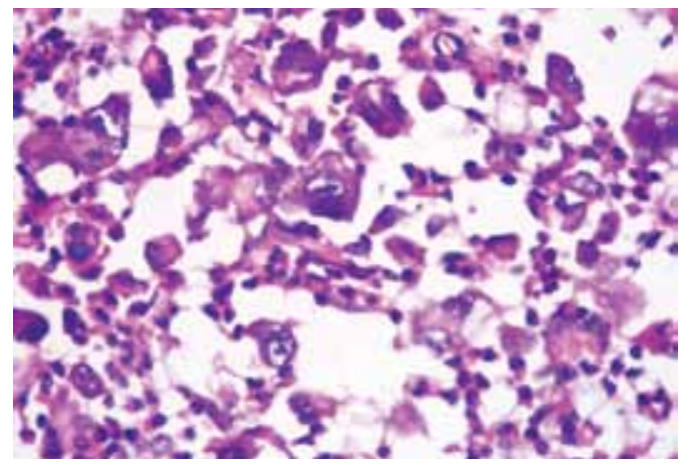

Figure 4. Anaplastic carcinoma showing hyperchromatic pleomorphic nuclei (HE stain, X400). 
papillary carcinoma (fig 1 and 2). Anaplastic carcinoma was detected in one case (fig 3 and 4).

Out of 90 patients, histopathological diagnosis was available in 20 patients. Comparison between FNAC finding and histopathological findings is shown in Table 2.

The sensitivity, specificity, false positive rate, false negative rate and diagnostic accuracy of FNAC for detection of malignant lesions was calculated and shown in Table 3.

Significant agreement was observed between FNAC and histopathology results as indicated by kappa (0.69) and $p$ value (0.001).

\section{DISCUSSION}

Thyroid enlargement, whether diffuse or nodular, leads to a battery of investigations, mainly to rule out the possibility of a neoplasm or thyroiditis. FNAC is the first line of investigation and other investigations like ultrasonography, thyroid function test, thyroid scan and antibody levels are done subsequently for appropriate management. ${ }^{4}$ The sensitivity of thyroid FNAC ranges from 78-92\% and its specificity from $74-99 \%{ }^{5-11}$ In our study the sensitivity was $85.7 \%$ and specificity $92.3 \%$. This shows that FNAC is more specific than sensitive in detecting thyroid malignancy. The diagnostic accuracy for cytologic diagnosis was $90 \%$ which is comparable with other studies. ${ }^{9,12,13}$

False negative FNA cytology results occurred in 1 case $(14.38 \%)$ of our patients. This case was diagnosed as adenomatous goiter in FNAC. On histopathological examination it was diagnosed as follicular carcinoma. The high cellularity of the lesion could have lead to misdiagnosis in FNAC. This is consistent with reports in the literature that suggest a false negative rate of $3 \%-26 \%{ }^{14-17}$

In our study one case was diagnosed as follicular neoplasm which on histological examination was colloid goiter. The false positive rate in our study is $7.69 \%$ which agreed with other studies, in which the incidence of false positive FNA cytology results ranged from $7 \%$ to $16 \% .{ }^{14-17}$ This may be due to sampling error and cytological interpretation.

\section{CONCLUSION}

FNAC is rapid, simple, safe and cost effective diagnostic modality in the investigation of thyroid disease with high sensitivity, specificity and accuracy. It can be used as initial investigation for the diagnosis of thyroid disease. FNAC diagnosis of malignancy is significant and such patients should be subjected to surgery whereas unnecessary surgery can be avoided in benign lesions.

\section{REFERENCES}

1. Tabaqchali MA, Hanson JM, Johnson SJ, Wadehra V, LennardTW, Proud G. Thyroid aspiration cytology in Newcastle: a six year cytology/histology correlation study. Ann R Coll Surg Engl 2000;82:149-55.

2. Orell SR, Sterrett GF, Whitaker D. Thyroid, In:Fine needle aspiration cytology. Churchill Livingstone: New Delhi; 2005.pp 126.

3. Van Herle AJ, Rich P, Ljung BME et al. The thyroid nodule. Ann Intern Med 1982;96:221-32.

4. De Micco C, Zoro P, Garcia S et al. Thyroid peroxidase immunodetection as a tool to assist diagnosis of thyroid nodules on fine needle aspiration biopsy. Eur J Endocrinol 1994;131:474-9.

5. Ko HM, Jhu IK, Yang SH et al. Clinicopathologic analysis of fine needle aspiration cytology of the thyroid. A review of 1,613 cases and correlation with histopathologic diagnoses. Acta Cytol 2003;47:72732.

6. Ravetto C, Colombo L, Dottorini ME. Usefulness of fine needle aspiration in the diagnosis of thyroid carcinoma: a retrospective study in 37,895 patients. Cancer 2000;90:357-63.

7. Cap J, Ryska A, Rehorkova P, Hovorkova E, Kerekes Z, Pohnetalova D. Sensitivity and specificity of the fine needle aspiration biopsy of the thyroid: clinical point of view. Clin Endocrinol 1999;51:509-15.

8. Gharib H, Goellner JR, Johnson DA. Fine needle aspiration cytology of the thyroid: A 12 year experience with 11,000 biopsies. Clin Lab Med 1993;13:699-709.

9. Bista M, KC Toran, Regmi D, Maharjan M, Kafle P, Shrestha S. Diagnostic accuracy of fine needle aspiration cytology in thyroid swellings. J Nepal Health Res Counc 2011;9:14-6.

10. Guhamallick M, Sengupta S, Bhattacharya NK et al. Cytodiagnosis of thyroid lesions- usefulness and pitfalls: A study of 288 cases. J Cytol 2008;25:6-9.

11. Joqai S, AI-Jassar A, Temmim L, Dey P, Adesina AO, Amanquno HG. Fine needle aspiration cytology of the thyroid: a cytohistologic study with evaluation of discordant cases. Acta Cytol 2005;49:483-8.

12. Mahar SA, Husain A, Islam N. Fine needle aspiration cytology of thyroid nodule: Diagnostic accuracy and pitfalls. J Ayub Med Coll Abbottabad 2006;18:26-9.

13. Agarwal A, Mishra SK. Completion total thyroidectomy in the management of differentiated thyroid carcinoma. Aust N Z J Surg 1996;66:358-60.

14. Caraway NP, Sneige N, Samaan NA. Diagnostic pitfalls in thyroid fine-needle aspiration: a review of 394 cases. Diagn Cytopathol 1993;9:345-50.

15. Baloch ZW, Sack MJ, YU GH, Livolsi VA, Gupta PK. Fine needle aspiration of thyroid: an institutional experience. Thyroid 1998;8:5659.

16. Bakhos R, Selvaggi SM, Dejong S et al. Fine needle aspiration of the thyroid: rate and causes of cytohistopathologic discordance. Diagn cytopathol 2000;23:233-7.

17. Godinho-Matos L, Kocjan G, Kurtz A. Contribution of fine needle aspiration cytology to diagnosis and management of thyroid disease. J Clin Pathol 1992;45:391-5. 